\title{
RESEARCH
}

Open Access

\section{Efficacy of mesenchymal stem cells in animal models of lupus nephritis: a meta- analysis}

Tianbiao Zhou ${ }^{1 *}$, Chunling Liao ${ }^{1}$, Hong-Yan Li², Wenshan Lin', Shujun Lin ${ }^{1}$ and Hongzhen Zhong ${ }^{1}$

\begin{abstract}
Background: Lupus nephritis is usually manifested by proteinuria, active urinary sediment, hypertension, and renal failure and is a serious complication with more than 50\% occurrence in systemic lupus erythematosus patients. Mesenchymal stem cells (MSC) present remarkable immunomodulatory ability, and these cells are potential therapeutic agents for autoimmune disorders. In clinical trials, the effectiveness of MSC in the treatment of lupus nephritis is still controversial. A meta-analysis was performed to assess whether MSC can achieve good efficacy in the treatment of lupus nephritis in mice.
\end{abstract}

Methods: A comprehensive literature search was performed in Cochrane Library, ISI Web of Science, PubMed, and EMBASE from inception to Oct 1, 2019. Two authors independently extracted the data, which were pooled and calculated using RevMan 5.3.

Results: A total of 28 studies met the inclusion criteria. MSC treatment resulted in lower levels of ds-DNA (OR $=-$ $29.58,95 \% \mathrm{Cl}-29.58,-17.99 ; P<0.00001)$, ANA $(\mathrm{OR}=-70.93,95 \% \mathrm{Cl}-104.55,-37.32 ; P<0.0001), \mathrm{Scr}(\mathrm{OR}=-8.20$, $95 \% \mathrm{Cl}-12.71,-3.69 ; P=0.0004)$, BUN (OR $=-14.57,95 \% \mathrm{Cl}-20.50,-8.64 ; P<0.00001)$, proteinuria (OR $=-4.26$, $95 \% \mathrm{Cl}-5.15$ to $-3.37 ; P<0.00001)$, and renal sclerosis score $(\mathrm{OR}=-1.92,95 \% \mathrm{Cl}-2.66$ to $-1.18 ; P<0.00001)$, and MSC treatment could get higher levels of albumin. To detect the potential, the cytokines were also assessed, and the MSC treatment group had lower levels of IL-2, IL-12, IL-17, and IFN- $\gamma$ when compared with the control group. However, the difference was not notable for IL-4, IL-6, IL-10, TGF- $\beta$, MCP-1, TNF-a, Th1, Th17, Foxp3, or Tregs.

Conclusion: Our study confirmed that MSC treatment in an animal model for lupus nephritis in the studies included in the meta-analysis resulted in lower levels of ds-DNA, ANA, Scr, BUN, proteinuria, and renal sclerosis score, and MSC treatment could get higher levels of albumin.

Keywords: Systemic lupus erythematosus (SLE), Lupus nephritis, Mesenchymal stem cells, Efficacy, Meta-analysis

\section{Introduction}

Systemic lupus erythematosus (SLE) is a typical autoimmune disease characterised by the production of autoantibodies against nuclear antigens, which is associated with multiple organ manifestations including lupus nephritis [1]. Lupus nephritis is usually manifested by proteinuria, active urinary sediment, hypertension, and renal failure and is a serious complication with more than $50 \%$ occurrence in SLE patients [2]. The causes of

\footnotetext{
* Correspondence: zhoutb@aliyun.com

${ }^{1}$ Department of Nephrology, the Second Affiliated Hospital, Shantou

University Medical College, 515041, No. 69 Dongsha Road, Shantou, China Full list of author information is available at the end of the article
}

many individual SLE pathologies are poorly understood. Traditional therapy includes glucocorticoids, cyclophosphamide, cyclosporine $\mathrm{A}$, tacrolimus, mycophenolate mofetil, azathioprine, etc. However, toxic side effects are notable in some of the drugs mentioned above. Mesenchymal stem cells (MSC) are used to treat some autoimmune diseases and are considered a safer agent when patients are resistant to these conventional therapies mentioned above [3].

MSC are multipotent cells, and they have the capacity to self-renew and differentiate into the tissues of mesodermal origin $[4,5]$. They present immunomodulatory ability and are used as therapeutic agents for 
autoimmune disorders $[4,6,7]$. In clinical trials, the efficacy of MSC in the treatment of lupus nephritis is still controversial. The reason might be that there were many confounding factors among the patients in the studies, such as varying disease severity, different complications and the drugs used in combination. Furthermore, because 10 MSC products are currently approved globally and only 2 are used for immune modulatory effects in host vs graft reactions in humans $[8,9]$, there are rare confounding factors in studies on animals in vivo. In this study, we included studies on mice to assess the efficacy of MSC in the therapy of lupus nephritis in mice, in order to draw a more robust result for the effectiveness of MSC treatment for lupus nephritis.

\section{Materials and methods}

\section{Search strategy}

A comprehensive literature search, restricted to Englishlanguage literature, was performed in the Cochrane Library, Embase, ISI Web of Science, and PubMed databases up to Oct. 1, 2019, using the following search terms: (stem cells OR mesenchymal stem cells OR mesenchymal stromal cells OR multipotent stromal cells OR mesenchymal progenitor cells) AND (systemic lupus erythematosus OR SLE OR lupus nephritis OR LN). The references cited in the recruited articles were also checked to identify additional reports. The Preferred Reporting Items for Systematic Reviews and MetaAnalyses (PRISMA) checklist is presented in Additional file 1.

\section{Inclusion and exclusion criteria}

Inclusion criteria are as follows: (1) type of study: animal experiment that used mice, (2) object of the study: lupus nephritis; (3) interventions: MSC for treatment; and (4) outcome: efficacy.

Exclusion criteria are as follows: (1) reviews, case reports, letters, clinical studies, systematic reviews, and meta-analysis; (2) studies lacked the targeted indicators and were conducted in humans; and (3) the therapeutic regimen included other agents with unknown effects.

\section{Outcome measures}

The following data regarding the efficacy of MSC treatment were identified from the recruited investigations: ds-DNA, ANA, Scr, BUN, albumin, proteinuria, IgM, Foxp3, IL-2, IL-4, IL-6, IL-10, IL-12, IL-17, TGF- $\beta$, MCP-1, IFN- $\gamma$, TNF- $\alpha$, Th1, Th17, Tregs, and renal sclerosis score. When there were multiple groups for the MSC-treated group, we only included the data from the early treatment group. When disagreements happened, a discussion with a third reviewer was conducted to resolve it.

\section{Quality assessment}

The methodological quality was independently assessed by two investigators (Tianbiao Zhou and Chunling Liao) using the Cochrane Handbook for Interventions. The principal components used for the assessment of each investigation included attrition bias, detection bias, selection bias, reporting bias, and other bias. Each item was classified as low risk, high risk, or unclear, and the general risk of bias was determined by taking all items together for presentation in a risk bias graph.

\section{Statistical analysis}

We conducted a meta-analysis of all animal studies in mice using the data from the MSC therapy group and control group. Review Manager Version 5.3 and STATA 12.0 were used to calculate the results. Heterogeneity due to study variation was quantified using $I^{2}$ statistics. A fixed effect model was applied if the $p$ value was $\geq 0.1$, based on the test of heterogeneity. Otherwise, a random effects model was applied to pool the results. Weighted mean differences (WMDs) were used to express the continuous data, and 95\% confidence intervals (95\% CI) were tested for the recruited investigations with the Mantel-Haenszel (M-H) method. Sensitivity analysis was performed for studies with a total number of test animals less than 16. Publication bias was also tested by STATA software 12.0, using both Egger's linear regression method and Begg's rank correlation test. A $p$ value $<0.05$ was considered statistically significant.

\section{Results}

Search results

In this meta-analysis, the databases were searched and we only included studies in mice to assess the efficacy of MSC treatment in lupus nephritis. The flowchart for this process is shown in Fig. 1. The characteristics of the recruited investigations are presented in Table 1.

\section{Quality assessment}

The methodological quality of the included studies was regarded as acceptable, as most of the domains of the included studies were ranked as low or unclear risk of bias. Low risk of bias was mostly detected in selection bias, detection bias, reporting bias, and attrition bias. Unclear risk of bias mostly occurred in selection bias, performance bias, and detection bias. A summary of the risk of biases of the included studies is presented in Fig. 2.

\section{Assessment of ds-DNA levels}

Twenty-four studies $[10-15,18-30,32-35,36]$ were recruited. We extracted the data for further analysis, and the results showed that the MSC treatment group obtained a lower level of ds-DNA when compared with the non-MSC treatment group in lupus nephritis mice 


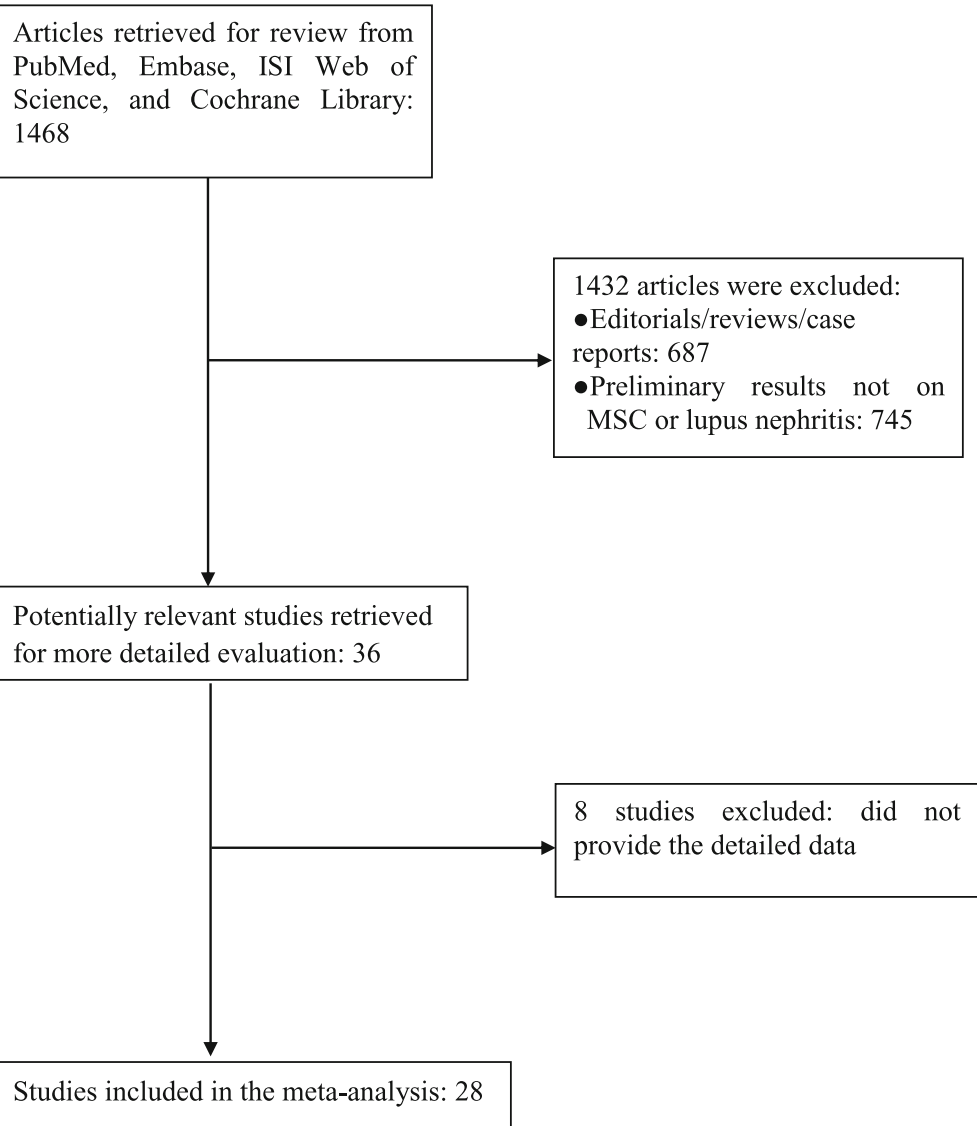

Fig. 1 Flow diagram of the selection process

$(\mathrm{OR}=-29.58, \quad 95 \% \quad$ CI $-29.58, \quad-17.99 ; \quad P<0.00001$;

Table 2 and Fig. 3).

\section{Assessment of ANA}

Four experimental studies [10, 14, 18, 36] were recruited into this meta-analysis to detect the efficacy of MSC in lupus nephritis treatment. The results indicated that the MSC group obtained lower levels of ANA than the control group $(\mathrm{OR}=-70.93,95 \% \mathrm{CI}-104.55,-37.32 ; P<$ 0.0001; Table 2).

\section{Assessment of Scr}

The Scr levels were also assessed and eight studies [11$13,17,23,24,31,37]$ were recruited. The results indicated that the difference in Scr levels between the MSC group and the control group was notable $(\mathrm{OR}=-8.20$, 95\% CI $-12.71,-3.69 ; P=0.0004$; Table 2), and the MSC group had lower levels of Scr.

\section{Assessment of BUN}

Seven studies [11, 13, 16, 22-24, 37] were included to assess the effects of MSC on BUN. The results showed that the difference in BUN levels between the MSC group and the control group was notable $(\mathrm{OR}=-14.57$, 95\% CI - 20.50, - 8.64; $P<0.00001$; Table 2), and the MSC group had lower levels of BUN.

\section{Assessment of albumin}

The albumin levels were also detected, and two studies $[10,23]$ were recruited. The results showed that the MSC group had higher levels of albumin, and the difference in albumin levels between the MSC group and the control group was notable $(\mathrm{OR}=7.22,95 \%$ CI 3.74, 10.69; $P<0.0001$; Table 2).

\section{Assessment of proteinuria}

Twenty-one studies $[10,11,14-17,20,21,23,24,27-$ $35,36,37]$ were recruited into this meta-analysis for the assessment of MSC in reducing proteinuria. We found that the MSC group obtained a lower level of proteinuria when compared with the control group $(\mathrm{OR}=-4.26$, 95\% CI -5.15 to $-3.37 ; P<0.00001$; Table 2 and Fig. 4 ).

\section{Assessment of IgM}

Three experimental studies $[10,19,30]$ were identified in this meta-analysis to detect the effect of MSC 


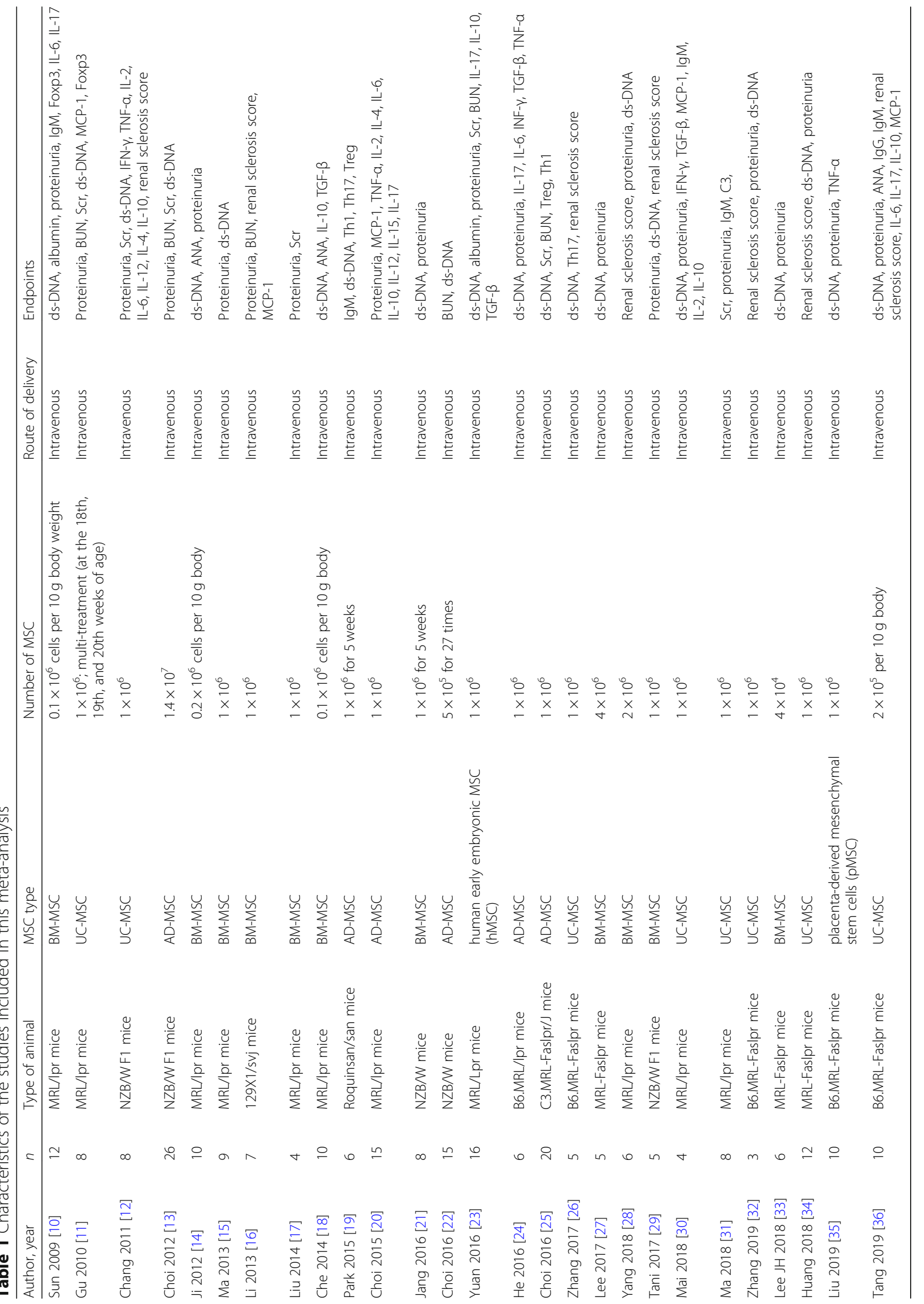



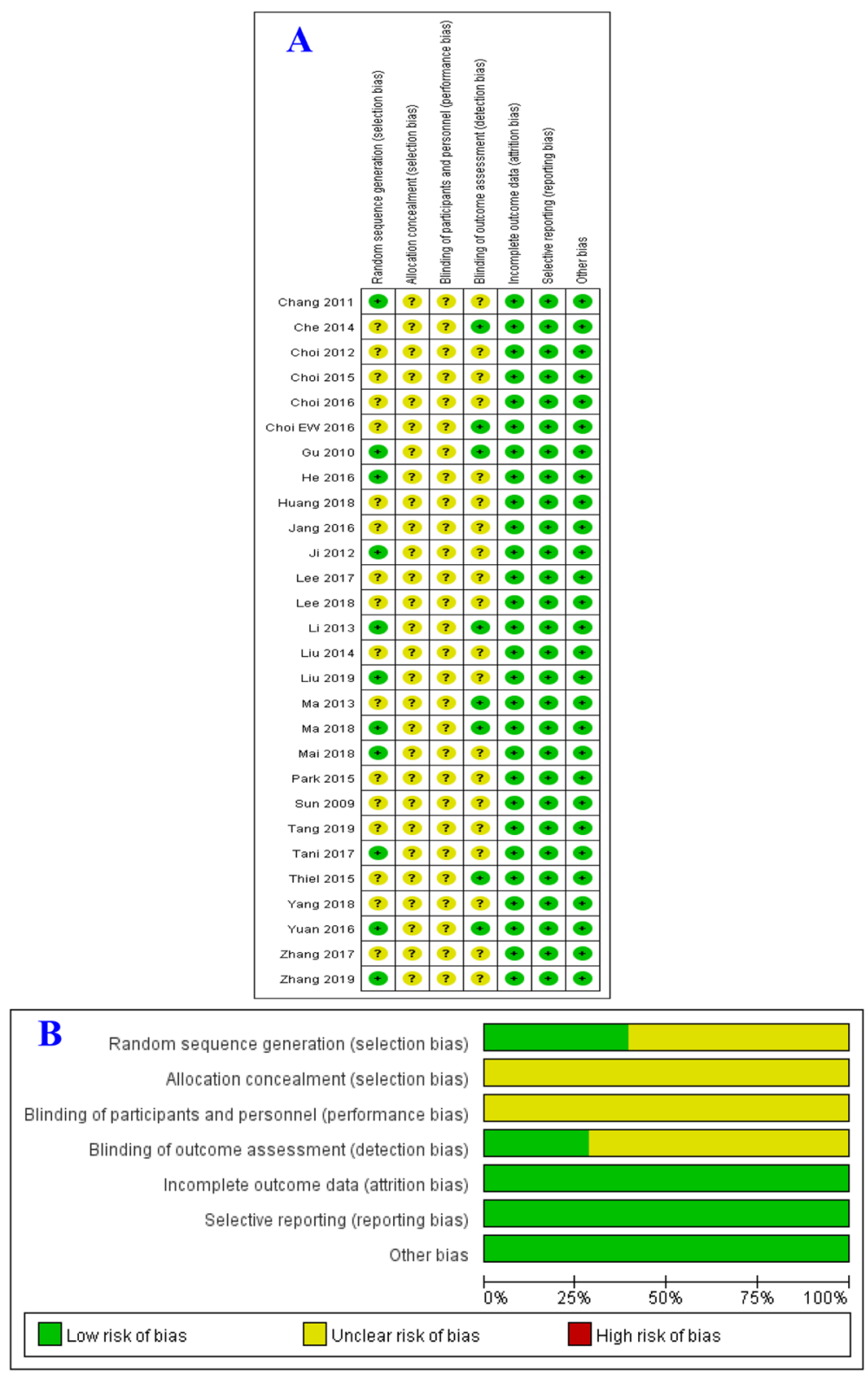

Fig. 2 a Aggregate risk of bias graph for each experimental animal studies. b Risk of bias summary

on IgM in lupus nephritis treatment. The results showed that the difference in IgM levels between the MSC group and the control group was not notable $(\mathrm{OR}=-4437.90, \quad 95 \%$ CI $-12,581.07,3705.28 ; \quad P=$ 0.29 ; Table 2).

\section{Assessment of ILs}

The levels of IL-2, IL-4, IL-6, IL-10, IL-12, and IL-17 were detected; four studies [12, 16, 20, 30] for IL-2, two studies $[12,20]$ for IL-4, seven studies $[10,12,16,20,24$, $36,37]$ for IL-6, six studies [12, 16, 18, 20, 30, 36] for IL10 , three studies $[12,16,20]$ for IL-12, and five studies $[10,20,24,25,36]$ for IL-17 were included for the assessment of the effect of MSC treatment on ILs. Interestingly, the MSC treatment group had a lower level of IL-2, IL-12, and IL-17 when compared with the control group (IL-2: OR $=-50.86,95 \% \mathrm{CI}-78.76,-22.96 ; P=$ 0.0004; IL-12: OR $=-328.24,95 \%$ CI $-652.20,-4.29$; $P=0.05 ;$ IL-17: OR $=-36.40,95 \%$ CI $-65.88,-6.93$; $P=0.02$; Table 2). The levels of IL-4, IL-6, and IL-10 in the MSC group were lower than those in the control group, but the differences were not statistically significant (IL-4: $\mathrm{OR}=-92.42,95 \% \mathrm{CI}-332.33,147.49 ; P=$ 0.45; IL-6: $\mathrm{OR}=-33.55,95 \% \mathrm{CI}-83.31,16.21 ; P=0.19$; IL-10: $\quad$ OR $=-29.67,95 \% \quad C I-68.25,8.91 ; \quad P=0.13$; Table 2). 
Table 2 Meta-analysis of the efficacy of MSC in the therapy of lupus nephritis

\begin{tabular}{|c|c|c|c|c|c|}
\hline Indicators & $\begin{array}{l}\text { Studies } \\
\text { Number }\end{array}$ & $\begin{array}{l}Q \text { test } \\
p \text { value }\end{array}$ & $\begin{array}{l}\text { Model } \\
\text { selected }\end{array}$ & $\begin{array}{l}\text { OR/WMD } \\
(95 \% \mathrm{Cl})\end{array}$ & $p$ \\
\hline ds-DNA & 24 & $<0.00001$ & Random & $-29.58(-41.18,-17.99)$ & $<0.00001$ \\
\hline ANA & 4 & $<0.00001$ & Random & $-70.93(-104.55,-37.32)$ & $<0.0001$ \\
\hline Scr & 8 & $<0.00001$ & Random & $-8.20(-12.71,-3.69)$ & 0.0004 \\
\hline BUN & 7 & $<0.00001$ & Random & $-14.57(-20.50,-8.64)$ & $<0.00001$ \\
\hline Albumin & 2 & 0.10 & Random & $7.22(3.74,10.69)$ & $<0.0001$ \\
\hline Proteinuria & 21 & $<0.00001$ & Random & $-4.26(-5.15,-3.37)$ & $<0.00001$ \\
\hline $\lg M$ & 3 & $<0.00001$ & Random & $-4437.90(-12,581.07,3705.28)$ & 0.29 \\
\hline $\mathrm{IL}-2$ & 4 & $<0.00001$ & Random & $-50.86(-78.76,-22.96)$ & 0.0004 \\
\hline IL-4 & 2 & $<0.0001$ & Random & $-92.42(-332.33,147.49)$ & 0.45 \\
\hline IL-6 & 7 & $<0.00001$ & Random & $-33.55(-83.31,16.21)$ & 0.19 \\
\hline IL-10 & 6 & $<0.00001$ & Random & $-29.67(-68.25,8.91)$ & 0.13 \\
\hline $\mathrm{IL}-12$ & 3 & $<0.00001$ & Random & $-328.24(-652.20,-4.29)$ & 0.05 \\
\hline IL-17 & 5 & $<0.00001$ & Random & $-36.40(-65.88,-6.93)$ & 0.02 \\
\hline TGF- $\beta$ & 3 & $<0.00001$ & Random & $-0.09(-2.90,2.72)$ & 0.95 \\
\hline MCP-1 & 2 & $<0.00001$ & Random & $-5917.71(-17,303.66,5468.23)$ & 0.31 \\
\hline $\mathrm{IFN}-\gamma$ & 4 & $<0.00001$ & Random & $-240.24(-364.73,-115.75)$ & 0.0002 \\
\hline TNF-a & 6 & $<0.00001$ & Random & $-74.71(-167.69,18.28)$ & 0.12 \\
\hline Th1 & 3 & $<0.00001$ & Random & $-6.37(-13.12,0.37)$ & 0.06 \\
\hline Th17 & 4 & $<0.00001$ & Random & $-0.15(-0.57,0.27)$ & 0.48 \\
\hline Foxp3 & 2 & 0.09 & Random & $1.21(-0.58,3.01)$ & 0.19 \\
\hline Treg & 3 & $<0.00001$ & Random & $4.73(-1.51,10.97)$ & 0.14 \\
\hline Renal sclerosis score & 10 & $<0.00001$ & Random & $-1.92(-2.66,-1.18)$ & $<0.00001$ \\
\hline
\end{tabular}

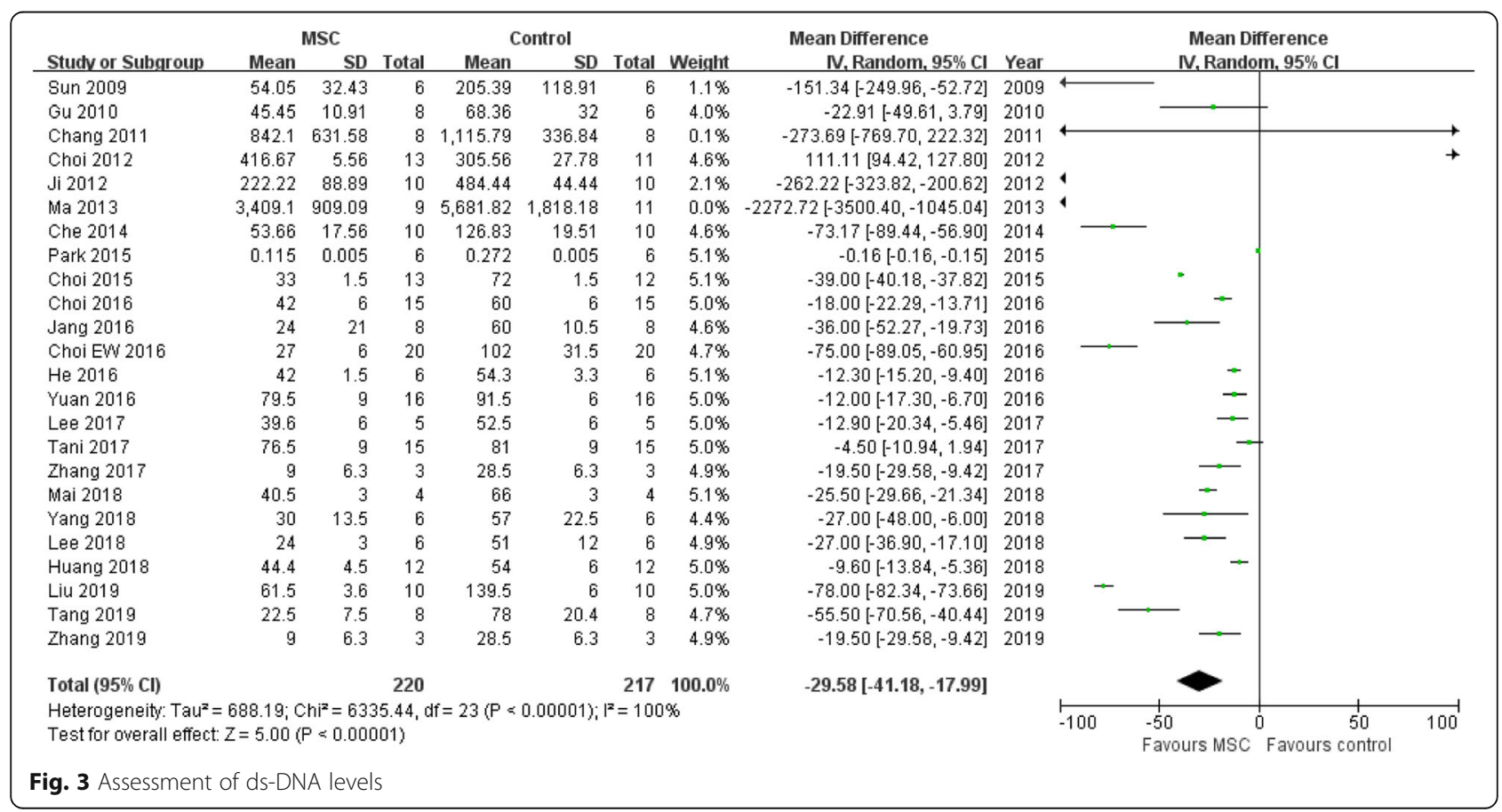




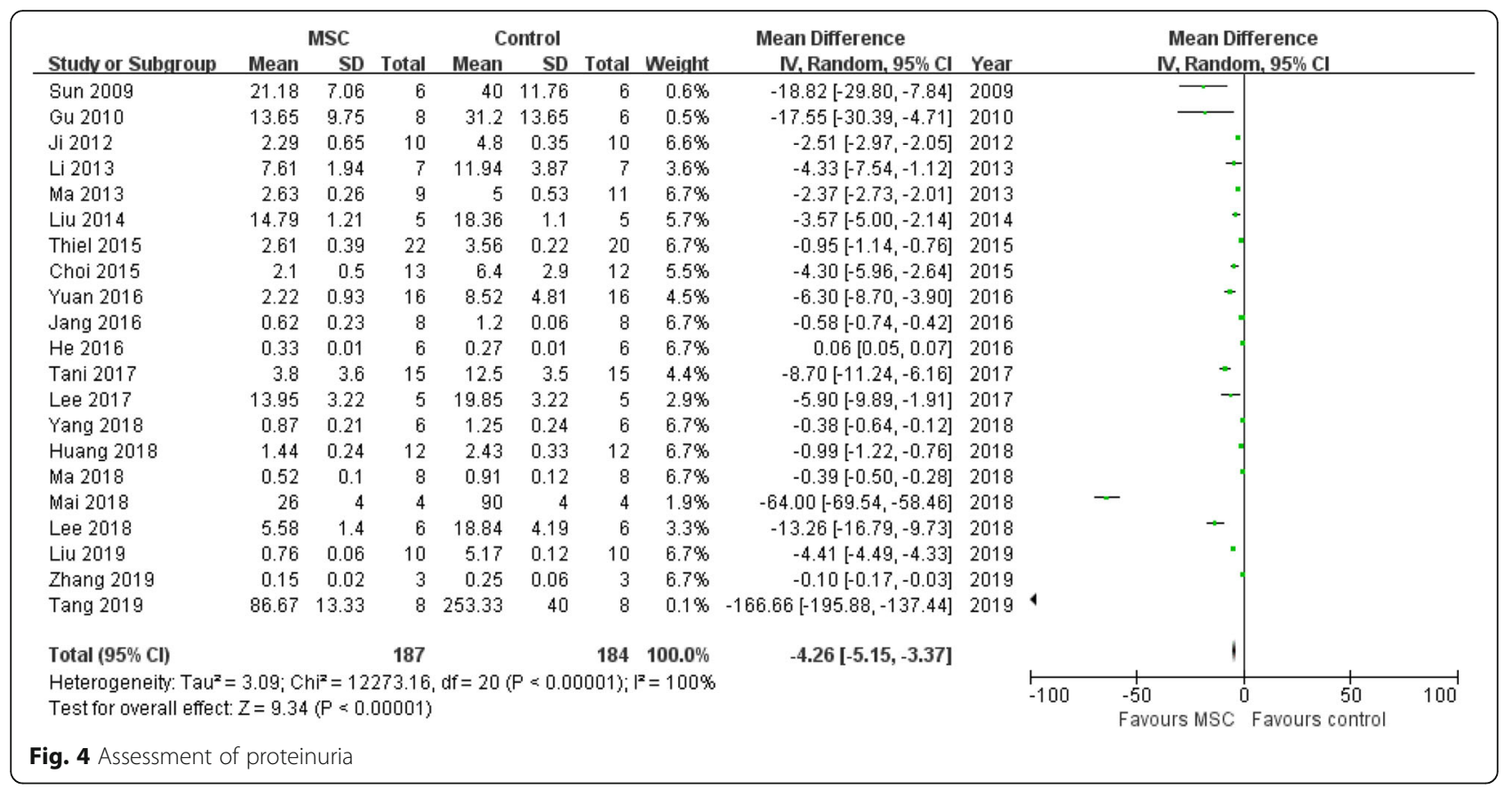

\section{Assessment of other cytokines}

The levels of TGF- $\beta$, MCP-1, IFN- $\gamma$, TNF- $\alpha$, Th1, Th17, Foxp3, and Tregs were detected; three studies [10, 18, 24] for TGF- $\beta$, two studies [11, 37] for MCP-1, four studies $[12,20,24,30]$ for IFN- $\gamma$, six studies $[12,16,20,24,35$, 37] for TNF- $\alpha$, three studies [19, 23, 37] for Th1, four studies $[19,23,26,36]$ for Th17, two studies $[10,11]$ for Foxp3, and three studies $[19,23,36]$ for Tregs were included for the assessment of the effect of MSC treatment on other cytokines. Interestingly, the MSC treatment group had a lower level of IFN- $\gamma$ when compared with the control group $(\mathrm{OR}=-240.24,95 \% \mathrm{CI}-364.73,-115.75$; $P=0.0002$; Table 2). The levels of TGF- $\beta$, MCP-1, TNF- $\alpha$, Th1, and Th17 in the MSC group were lower than those in the control group, but the differences were not statistically significant (TGF- $\beta$ : OR $=-0.09,95 \% \mathrm{CI}-2.90,2.72$; $P=0.95$; MCP-1: OR $=-5917.71,95 \%$ CI $-17,303.66$,
5468.23; $P=0.31$; TNF- $\alpha$ : OR $=-74.71,95 \%$ CI -167.69 , 18.28; $P=0.12$; Th1: $\mathrm{OR}=-6.37,95 \% \mathrm{CI}-13.12,0.37$; $P=0.06$; Th17: OR $=-0.15,95 \%$ CI $-0.57,0.27 ; P=0.48$; Table 2). However, the levels of Foxp3 and Tregs in the MSC group were higher than those in the control group, but the differences were not statistically significant (Foxp3: $\mathrm{OR}=1.21,95 \% \mathrm{CI}-0.58,3.01 ; P=0.19$; Treg: $\mathrm{OR}=4.73$, 95\% CI - 1.51, 10.97; $P=0.14$; Table 2).

\section{Assessment of renal sclerosis score}

Ten studies [12, 16, 19, 26, 28, 32, 34, 35, 36, 37] were included for the assessment of the effect of MSC on renal sclerosis, and the renal sclerosis score was used. The results indicated that the MSC group had a lower renal sclerosis score when compared with the control group $(\mathrm{OR}=-1.92,95 \% \mathrm{CI}-2.66$ to $-1.18 ; P<0.00001$; Table 2 and Fig. 5).

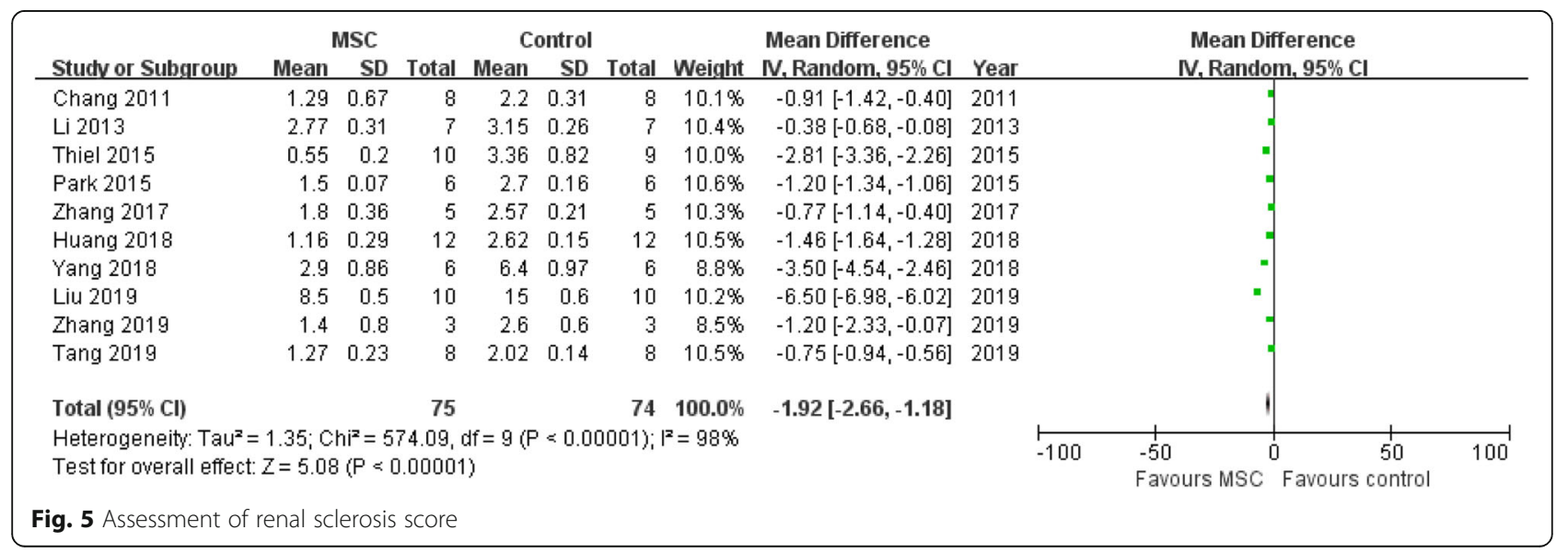




\section{Sensitivity analysis}

We performed sensitivity analysis for the studies with a total number of test animals less than 16 and found that the MSC treatment group obtained a lower level of dsDNA when compared with non-MSC treatment in lupus nephritis mice $(\mathrm{OR}=-36.38,95 \%$ CI $-52.46,-20.30$; $P<0.00001)$. When compared with the non-MSC treatment group, the MSC treatment group had a lower level of Scr $(\mathrm{OR}=-5.97,95 \%$ CI $-11.55,-0.39 ; P=0.04)$, BUN $(\mathrm{OR}=-16.74,95 \% \mathrm{CI}-23.77,-9.70 ; P<0.00001)$, and proteinuria $(\mathrm{OR}=-3.46,95 \% \mathrm{CI}-4.90,-2.03 ; P<$ $0.00001)$ as well as a lower renal sclerosis score $(\mathrm{OR}=-$ 2.48, 95\% CI - 3.98, $-0.97 ; P=0.001$ ).

\section{Publication bias}

A funnel plot generated for the primary outcome using Egger's test $(P=0.003)$ and Begg's test $(P=0.002)$ suggested that there was publication bias (Fig. 6).

\section{Discussion}

In this study, we included studies in mice, and the results might be more robust than those from clinical trials. In the past decades, glucocorticoids, cyclophosphamide, calcineurin inhibitors (cyclosporine A and tacrolimus), mycophenolate mofetil, rituximab, tripterygium wilfordii, etc., have been used in the treatment of lupus nephritis and were also mentioned in the KDIGO 2012 guidelines [38]. MSC has been reported to be a good agent for the treatment of some autoimmune diseases in the past decades $[3,39,40]$.

MSC treatment resulted in lower levels of ds-DNA, ANA, Scr, BUN, proteinuria, and renal sclerosis score, and MSC treatment could get a higher level of albumin. These results indicated that MSC might be a good agent for the treatment of lupus nephritis in mice. To detect the potential, cytokines were also assessed, and we found that the MSC treatment group had lower levels of IL-2, IL-12, IL-17, and IFN- $\gamma$ when compared with the control group. However, the difference was not notable for IL-4, IL-6, IL-10, TGF- $\beta$, MCP-1, TNF- $\alpha$, Th1, Th17, Foxp3, and Tregs. The cytokines mentioned above might indicate that MSC treatment might play a protective role by regulating the signalling pathways of IL-2, IL-12, IL-17, and IFN- $\gamma$, but not IL-4, IL-6, IL-10, TGF- $\beta$, MCP- 1 , TNF- $\alpha$, Th1,Th17, Foxp3, or Tregs. Lupus nephritis is a typical autoimmune disease characterised by the production of autoantibodies against nuclear antigens as well as renal involvement. Cytokines might take part in this process. The sample sizes for the meta-analyses were small, and more well-designed studies should be performed to confirm these findings.

In a previous study, there was only one meta-analysis assessing the efficacy of MSC in the therapy of kidney disease. Wang et al. [41] performed a meta-analysis including 21 studies to assess the efficacy of MSC treatment on renal failure and found that the elevated Scr level was reduced in the animal models with renal failure following MSC therapy. Furthermore, we also reviewed the systematic review and meta-analysis for assessing the efficacy of MSC treatment on autoimmune diseases. Liu et al. [42] included 48 studies to evaluate whether the MSC can improve the outcomes of rheumatoid arthritis, and the results indicated that MSC treatment consistently exhibited therapeutic benefits. Hynes et al. [43]

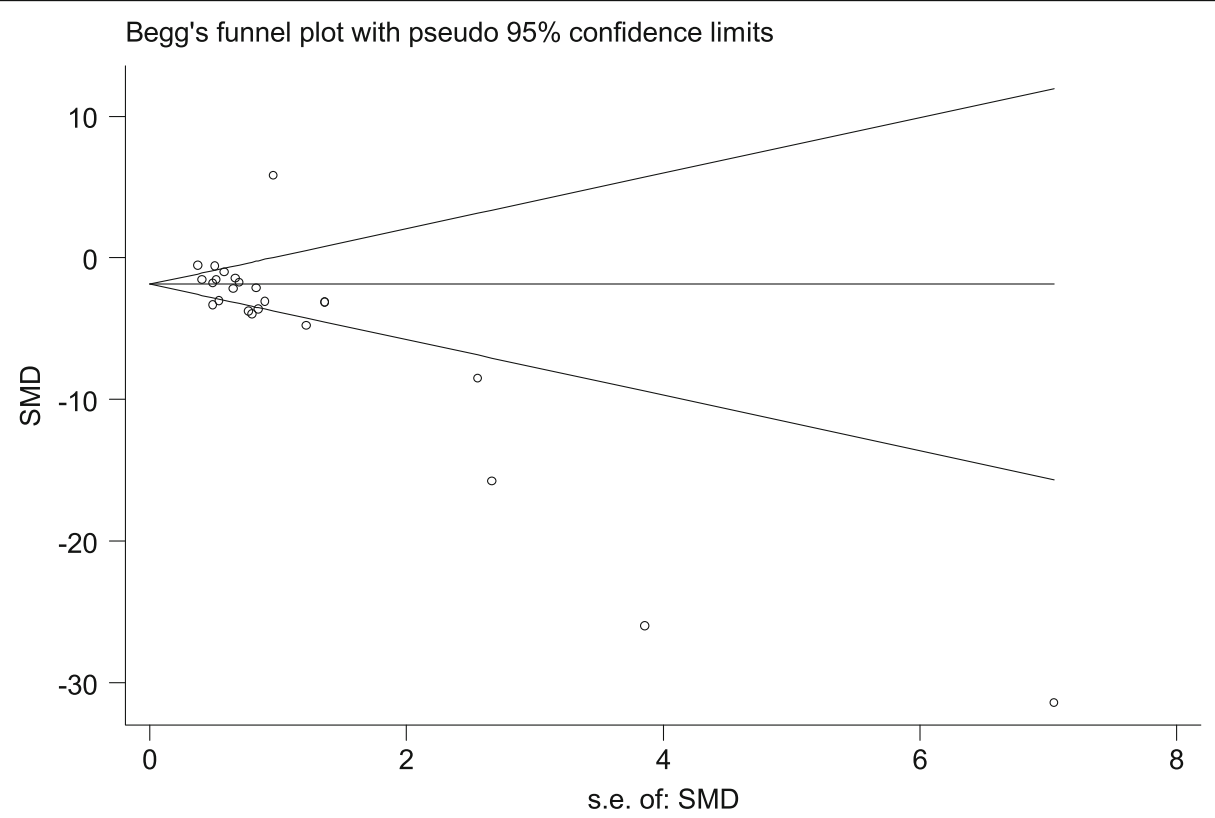

Fig. 6 Publication bias 
performed a systematic review of 30 studies to investigate the evidence for the therapeutic efficacy of MSC treatment in arthritis and indicated that 19 demonstrated positive outcomes while 11 studies failed to demonstrate positive effects. There was no previous meta-analysis on the relationship between MSC treatment and lupus nephritis.

Quality assessment was performed in this metaanalysis. Most of the included studies were determined to have low or unclear risk of bias and were regarded as good quality. However, the publication bias test was performed and the result indicated publication bias. Most of the included studies lacked observer blinding, which will affect the robustness of the results. Furthermore, the sample size of most of the included studies was small (the total number of test animals was less than 16). Different types of MSC were included. These factors will affect the robustness of the results. More well-designed studies should be performed in the future. In this metaanalysis, we did not perform a meta-analysis for clinical trials because there might be less heterogenicity among studies with murine models of lupus kidney dysfunction for meta-analysis. The results in mice indicated that MSC treatment can have a good effect on lupus nephritis, and it indicated that more well-designed studies on MSC treatment for lupus nephritis in the clinic are needed in the future.

\section{Conclusions}

In our meta-analysis, we found that MSC treatment resulted in lower levels of ds-DNA, ANA, Scr, BUN, proteinuria, and renal sclerosis score in lupus nephritis for mice, and MSC treatment could get a higher level of albumin. Our meta-analysis also indicated that the MSC treatment group also had lower levels of IL-2, IL-12, IL17 , and IFN- $\gamma$ when compared with the control group in lupus nephritis mice. However, more studies are needed to confirm these associations in the future.

\section{Supplementary information}

The online version of this article (https://doi.org/10.1186/s13287-019-1538-9) contains supplementary material, which is available to authorized users.

Additional file 1. The Preferred Reporting Items for systematic Reviews and Meta-Analyses (PRISMA) checklist.

\section{Abbreviations}

Cl: Confidence intervals; M-H: Mantel-Haenszel; MSC: Mesenchymal stem cells; SLE: Systemic lupus erythematosus; WMDs: Weighted mean differences

\section{Acknowledgements}

The authors would like to gratefully acknowledge the most helpful comments on this paper received from Professor Hong Qian, Karolinska Institutet.

\section{Authors' contributions}

TBZ contributed to the conception and design of the study. TBZ, HYL, and CLL were responsible for collection of data and performing the statistical analysis and manuscript preparation. WSL, SJL, and HZZ were responsible for checking the data. All authors were responsible for drafting the manuscript and read and approved the final version.

\section{Funding}

This study was supported by the Guangzhou Medical Key Discipline Construction Project (2017-2019), the Natural Science Foundation of the Guangdong Province (no. 2015A030310386), and Guangdong Medical Science and Technology Research Fund Project (no. A2018336).

\section{Availability of data and materials}

Not applicable.

Ethics approval and consent to participate

Not applicable.

\section{Consent for publication}

Not applicable.

\section{Competing interests}

The authors declare that they have no competing interests.

\section{Author details}

'Department of Nephrology, the Second Affiliated Hospital, Shantou University Medical College, 515041, No. 69 Dongsha Road, Shantou, China. 2Department of Nephrology, Huadu District People's Hospital of Guangzhou, Southern Medical University, Guangzhou 510800, China.

Received: 4 November 2019 Revised: 11 December 2019

Accepted: 20 December 2019 Published online: 04 February 2020

\section{References}

1. Wardowska A, Komorniczak M, Bullo-Piontecka B, Debska-Slizien MA, Pikula M. Transcriptomic and epigenetic alterations in dendritic cells correspond with chronic kidney disease in lupus nephritis. Front Immunol. 2019;10:2026.

2. Ji J, Fu T, Dong C, Zhu W, Yang J, Kong X, et al. Targeting HMGB1 by ethyl pyruvate ameliorates systemic lupus erythematosus and reverses the senescent phenotype of bone marrow-mesenchymal stem cells. Aging. 2019;11(13):4338-53

3. Wang $\mathrm{D}$, Zhang $\mathrm{H}$, Liang J, Wang $H$, Hua B, Feng $X$, et al. A long-term follow-up study of allogeneic mesenchymal stem/stromal cell transplantation in patients with drug-resistant systemic lupus Erythematosus. Stem Cell Reports. 2018;10(3):933-41.

4. Dias IE, Pinto PO, Barros LC, Viegas CA, Dias IR, Carvalho PP. Mesenchymal stem cells therapy in companion animals: useful for immune-mediated diseases? BMC Vet Res. 2019;15(1):358.

5. Liu R, Zhang X, Fan Z, Wang Y, Yao G, Wan X, et al. Human amniotic mesenchymal stem cells improve the follicular microenvironment to recover ovarian function in premature ovarian failure mice. Stem Cell Res Ther. 2019;10(1):299.

6. Andrukhov O, Behm C, Blufstein A, Rausch-Fan X. Immunomodulatory properties of dental tissue-derived mesenchymal stem cells: implication in disease and tissue regeneration. World J Stem Cells. 2019;11(9):604-17.

7. Yu S, Cheng Y, Zhang L, Yin Y, Xue J, Li B, et al. Treatment with adipose tissue-derived mesenchymal stem cells exerts anti-diabetic effects, improves long-term complications, and attenuates inflammation in type 2 diabetic rats. Stem Cell Res Ther. 2019;10(1):333.

8. Mendt M, Rezvani K, Shpall E. Mesenchymal stem cell-derived exosomes for clinical use. Bone Marrow Transplant. 2019;54(Suppl 2):789-92.

9. Coppin L, Sokal E, Stephenne X. Thrombogenic risk induced by intravascular mesenchymal stem cell therapy: current status and future perspectives. Cells. 2019:8(10):E1160.

10. Sun L, Akiyama K, Zhang H, Yamaza T, Hou Y, Zhao S, et al. Mesenchymal stem cell transplantation reverses multiorgan dysfunction in systemic lupus erythematosus mice and humans. Stem Cells. 2009:27(6):1421-32.

11. Gu Z, Akiyama K, Ma X, Zhang H, Feng X, Yao G, et al. Transplantation of umbilical cord mesenchymal stem cells alleviates lupus nephritis in MRL/pr mice. Lupus. 2010;19(13):1502-14. 
12. Chang JW, Hung SP, Wu HH, Wu WM, Yang AH, Tsai HL, et al. Therapeutic effects of umbilical cord blood-derived mesenchymal stem cell transplantation in experimental lupus nephritis. Cell Transplant. 2011;20(2): 245-57.

13. Choi EW, Shin IS, Park SY, Park JH, Kim JS, Yoon EJ, et al. Reversal of serologic, immunologic, and histologic dysfunction in mice with systemic lupus erythematosus by long-term serial adipose tissue-derived mesenchymal stem cell transplantation. Arthritis Rheum. 2012;64(1):243-53.

14. Ji S, Guo Q, Han Y, Tan G, Luo Y, Zeng F. Mesenchymal stem cell transplantation inhibits abnormal activation of Akt/GSK3beta signaling pathway in T cells from systemic lupus erythematosus mice. Cell Physiol Biochem. 2012;29(5-6):705-12.

15. Ma X, Che N, Gu Z, Huang J, Wang D, Liang J, et al. Allogenic mesenchymal stem cell transplantation ameliorates nephritis in lupus mice via inhibition of B-cell activation. Cell Transplant. 2013;22(12):2279-90.

16. Li Y, Raman I, Du Y, Yan M, Min S, Yang J, et al. Kallikrein transduced mesenchymal stem cells protect against anti-GBM disease and lupus nephritis by ameliorating inflammation and oxidative stress. PLoS One. 2013;8(7):e67790.

17. Liu RH, Li YQ, Zhou WJ, Shi YJ, Ni L, Liu GX. Supplementing mesenchymal stem cells improves the therapeutic effect of hematopoietic stem cell transplantation in the treatment of murine systemic lupus erythematosus. Transplant Proc. 2014;46(5):1621-7.

18. Che N, Li X, Zhang L, Liu R, Chen H, Gao X, et al. Impaired B cell inhibition by lupus bone marrow mesenchymal stem cells is caused by reduced CCL2 expression. J Immunol. 2014;193(10):5306-14.

19. Park MJ, Kwok SK, Lee SH, Kim EK, Park SH, Cho ML. Adipose tissue-derived mesenchymal stem cells induce expansion of interleukin-10-producing regulatory $B$ cells and ameliorate autoimmunity in a murine model of systemic lupus erythematosus. Cell Transplant. 2015;24(11):2367-77.

20. Choi EW, Shin IS, Song JW, Yun TW, Yang J, Choi KS, et al. Transplantation of adipose tissue-derived mesenchymal stem cells prevents the development of lupus dermatitis. Stem Cells Dev. 2015;24(17):2041-51.

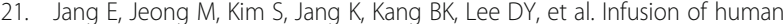
bone marrow-derived mesenchymal stem cells alleviates autoimmune nephritis in a lupus model by suppressing follicular helper T-cell development. Cell Transplant. 2016;25(1):1-15.

22. Choi EW, Lee HW, Shin IS, Park JH, Yun TW, Youn HY, et al. Comparative efficacies of long-term serial transplantation of syngeneic, allogeneic, xenogeneic, or CTLA4lg-overproducing xenogeneic adipose tissue-derived mesenchymal stem cells on murine systemic lupus Erythematosus. Cell Transplant. 2016;25(6):1193-206.

23. Yuan L, Xiao ZT, Huang XZ, Wu MJ, Shi H, Liu AF. Human embryonic mesenchymal stem cells alleviate pathologic changes of MRL/Lpr mice by regulating Th7 cell differentiation. Ren Fail. 2016;38(9):1432-40.

24. He X, Zhang Y, Zhu A, Zeng K, Zhang X, Gong L, et al. Suppression of interleukin 17 contributes to the immunomodulatory effects of adiposederived stem cells in a murine model of systemic lupus erythematosus. Immunol Res. 2016;64(5-6):1157-67.

25. Choi EW, Lee M, Song JW, Shin IS, Kim SJ. Mesenchymal stem cell transplantation can restore lupus disease-associated miRNA expression and Th1/Th2 ratios in a murine model of SLE. Sci Rep. 2016;6:38237.

26. Zhang Z, Feng R, Niu L, Huang S, Deng W, Shi B, et al. Human umbilical cord mesenchymal stem cells inhibit T follicular helper cell expansion through the activation of iNOS in lupus-prone B6.MRL-Fas (lpr) mice. Cell Transplant. 2017;26(6):1031-42.

27. Lee HK, Kim HS, Kim JS, Kim YG, Park KH, Lee JH, et al. CCL2 deficient mesenchymal stem cells fail to establish long-lasting contact with $T$ cells and no longer ameliorate lupus symptoms. Sci Rep. 2017;7:41258.

28. Yang X, Yang J, Li X, Ma W, Zou H. Bone marrow-derived mesenchymal stem cells inhibit T follicular helper cell in lupus-prone mice. Lupus. 2018; 27(1):49-59.

29. Tani C, Vagnani S, Carli L, Querci F, Kuhl AA, Spieckermann S, et al. Treatment with allogenic mesenchymal stromal cells in a murine model of systemic lupus erythematosus. Int J Stem Cells. 2017;10(2):160-8.

30. Mai S, Zou L, Tian X, Liao X, Luan Y, Han X, et al. Double-edged effect of hydroxychloroquine on human umbilical cord-derived mesenchymal stem cells treating lupus nephritis in MRL/lpr mice. Mol Pharm. 2018;15(5):1800-13.

31. Ma H, Liu C, Shi B, Zhang Z, Feng R, Guo M, et al. Mesenchymal stem cells control complement $\mathrm{C} 5$ activation by factor $\mathrm{H}$ in lupus nephritis. EBioMedicine. 2018;32:21-30.
32. Zhang Z, Niu L, Tang X, Feng R, Yao G, Chen W, et al. Mesenchymal stem cells prevent podocyte injury in lupus-prone B6.MRL-Faslpr mice via polarizing macrophage into an anti-inflammatory phenotype. Nephrol Dial Transplant. 2019;34(4):597-605.

33. Lee JH, Lee HK, Kim HS, Kim JS, Ji AY, Lee JS, et al. CXCR3-deficient mesenchymal stem cells fail to infiltrate into the nephritic kidney and do not ameliorate lupus symptoms in MRL. Fas (Ipr) mice. Lupus. 2018;27(11): 1854-9.

34. Huang S, Wu S, Zhang Z, Deng W, Fan J, Feng R, et al. Mesenchymal stem cells induced CD4+ T cell apoptosis in treatment of lupus mice. Biochem Biophys Res Commun. 2018;507(1-4):30-5.

35. Liu J, Lu X, Lou Y, Cai Y, Cui W, Wang J, et al. Xenogeneic transplantation of human placenta-derived mesenchymal stem cells alleviates renal injury and reduces inflammation in a mouse model of lupus nephritis. Biomed Res Int. 2019:2019:9370919.

36. Tang X, Li W, Wen X, Zhang Z, Chen W, Yao G, et al. Transplantation of dental tissue-derived mesenchymal stem cells ameliorates nephritis in lupus mice. Ann Transl Med. 2019;7(7):132.

37. Thiel A, Yavanian G, Nastke MD, Morales P, Kouris NA, Kimbrel EA, et al. Human embryonic stem cell-derived mesenchymal cells preserve kidney function and extend lifespan in NZB/W F1 mouse model of lupus nephritis. Sci Rep. 2015:5:17685.

38. Chapter 7: Idiopathic membranous nephropathy. Kidney Int Suppl. 2012;2(2): 186-97.

39. Jiang $W, \mathrm{Xu}$ J. Immune modulation by mesenchymal stem cells. Cell Prolif. 2019:e12712. https://doi.org/10.1111/cpr.12712.

40. Chen Y, Yu Q, Hu Y, Shi Y. Current research and use of Mesenchymal stem cells in the therapy of autoimmune diseases. Curr Stem Cell Res Ther. 2019: 14(7):579-82.

41. Wang Y, He J, Pei X, Zhao W. Systematic review and meta-analysis of mesenchymal stem/stromal cells therapy for impaired renal function in small animal models. Nephrology (Carlton). 2013;18(3):201-8.

42. Liu L, Wong CW, Han M, Farhoodi HP, Liu G, Liu Y, et al. Meta-analysis of preclinical studies of mesenchymal stromal cells to treat rheumatoid arthritis. EBioMedicine. 2019:47:563-77.

43. Hynes K, Bright R, Proudman S, Haynes D, Gronthos S, Bartold M. Immunomodulatory properties of mesenchymal stem cell in experimental arthritis in rat and mouse models: a systematic review. Semin Arthritis Rheum. 2016:46(1):1-19.

\section{Publisher's Note}

Springer Nature remains neutral with regard to jurisdictional claims in published maps and institutional affiliations.

Ready to submit your research? Choose BMC and benefit from:

- fast, convenient online submission

- thorough peer review by experienced researchers in your field

- rapid publication on acceptance

- support for research data, including large and complex data types

- gold Open Access which fosters wider collaboration and increased citations

- maximum visibility for your research: over $100 \mathrm{M}$ website views per year

At $\mathrm{BMC}$, research is always in progress.

Learn more biomedcentral.com/submissions 